\title{
José Martí, cronista de todos los tiempos. José Martí: Narrar desde el periodismo, EUNA, 2017
}

\section{José Martí, all-time Chronicler. José Martí: Narrar desde el periodismo [José Martí: Narrating from Journalism], EUNA, 2017}

\section{José Martí, cronista de todos os tempos. José Martí: Narrar desde el periodismo [José Martí, Narrando a partir do jornalismo] EUNA, 2017}

Andrés Mora-Ramírez

Recibido: 13 de agosto, 2018

DOI: https: //doi.org/10.15359/tdna.35-65.21

La publicación del libro José Martí: Narrar desde el periodismo, del Dr. Mauricio Núñez, por la Editorial de la Universidad Nacional (EUNA) de Costa Rica representa una valiosa contribución al enriquecimiento de la cultura en la comunidad universitaria costarricense y latinoamericana en general; pero será especialmente útil para quienes se forman en los campos de las ciencias de la comunicación, la literatura y

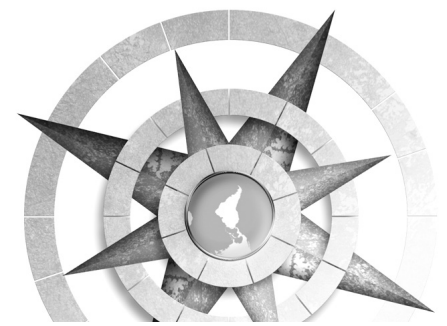


el marco del inmenso corpus de la producción martiana (solo para tener una idea de lo que esto significa, conviene recordar que la más reciente edición crítica de sus Obras completas, preparada por CLACSO y el Centro de Estudios Martianos, comprende 25 volúmenes).

El oficio del cronista en nuestra América tiene raíces hondas -que podríamos hurgar incluso hasta los tiempos de la colonia- y ha sido fundamental en el empeño de comprensión del devenir histórico del continente, de nuestros pueblos, de la compleja construcción de nuestras dolorosas repúblicas. Y de manera particular hacia finales del siglo XIX y principios del siglo XX, la crónica como género híbrido, en el que se articulan los registros periodísticos y literarios, da cuenta de los afanes de una vanguardia intelectual que intenta aprehender y comunicar para sus públicos latinoamericanos, a veces con conmovedora pasión, la profundidad de las transformaciones - sin precedentes- que se suceden en el mundo. Parafraseando a Renato Ortiz (1995), podríamos decir que hacen de la crónica el urgente llamado "para ajustar nuestro reloj al tiempo de las exigencias universales" de la Modernidad.

No debe sorprendernos, entonces, que José Martí, al igual que otros poetas, y escritores de su época, como Rubén Darío o Manuel Gutiérrez Nájera, en medio de su trabajo artístico, pero también de su trabajo político, incursionaran en el periodismo en el último cuarto del siglo XIX, vinculándose a periódicos latinoamericanos y estadounidenses como corresponsales: desde allí, por medio de cartas, relatos y crónicas de magistral elaboración, van horadando el camino de una construcción discursiva original y vigorosa.

En efecto, como nos lo recuerdan Froilán Escobar y Ernesto Rivera (2009), estos modernistas finiseculares, con su "exaltada manera de traspasar los límites”, y "con su empecinada vocación latinoamericanista y fundacional de pensar y ver el mundo desde este lado del mundo", fueron capaces de ir más allá de la economía informativa que exigía a las empresas periodísticas el modelo de producción de masas que se iba perfilando en virtud de las innovaciones tecnológicas que aceleraron el desarrollo de las redes de comunicación y de transporte global; y en ese ir más allá, alcanzaron "una forma comunicativa que traducía expresivamente el idioma de la realidad humana -que habla por medio de acontecimientos-, a las inusitadas musicalidades del lenguaje modernista".

Las crónicas seleccionadas para este libro tienen dos ejes temáticos en común: uno es el acercamiento de Martí, con admiración y juicio crítico, a los Estados Unidos de finales del siglo XIX, en pleno proceso de industrialización, y 
en concreto "a las estructuras que simbolizan la modernidad [...], enclavadas en la ciudad de Nueva York" (Núñez, 2016, p. 12), destino de migrantes de todo el mundo. El cronista se acerca a estos símbolos por medio de la narración y la interpretación de diferentes sucesos, toda vez que advierte en ellos, y en su surgimiento en ese centro multicultural, "creaciones que son portadoras de temas 'culminantes, perdurables y de valor humano'” (Núñez, 2016, p. 14), como nos dice el autor.

El otro eje es su mirada crítica del fenómeno de la expansión imperialista, a través del estudio de un conflicto político entre Estados Unidos y México (el caso Cutting) y lo que, en palabras del autor, evidencia la incapacidad de silencio de José Martí "ante todo acto que agrediese la soberanía o la integridad de cualquiera de los países latinoamericanos" (Núñez, 2016, p. 51).

Así pues, las crónicas martianas seleccionadas para esta edición son una muestra de lo mejor de la práctica del periodismo que hizo el escritor cubano: sus rasgos son el conocimiento y dominio del tema, la documentación rigurosa, la atención al detalle, el fino sentido del enfoque noticioso, el uso de estructuras textuales que le permitan moverse con fluidez; y a todo ello sumó su inconfundible estilo, su lenguaje, su ética y el vigor de su palabra que se proyecta a través de los siglos.
Es que "en Martí periodista - puntualiza el Dr. Núñez en uno de los ensayos- "era una constante su preocupación por la búsqueda de la verdad en la información, su insistencia en lograr la autenticidad en el mensaje mediante la confirmación de los hechos hasta donde le era posible, o sacando la mayor cantidad de datos de todas las fuentes a su alcance antes de narrarlos o emitir juicios" (Núñez, 2016, p. 52).

La intencionalidad que subyace a de cada uno de los textos del prócer cubano, da fe también de su gran labor pedagógica. Martí escribe para sus lectores latinoamericanos, a quienes quiere persuadir, como señala el Dr. Núñez, "del progreso técnico y sus posibilidades de unir a las personas"; escribe, sobre todo, para "los incrédulos de la modernidad o los que pudieran resistirse a reconocer lo grandioso y seguro de una obra nueva” (Núñez, 2016, pp. 26-27).

Pero el proyecto de modernidad que impulsa Martí, que se sabe un mediador cultural entre los mundos heterogéneos, diversos y contrastantes de las dos Américas, no es el de la simple reproducción acrítica, o la resignación ante lo que es enunciado como inevitable desde los centros del poder. Cabe recordar aquí lo que, sobre este punto, señala el crítico literario Luis Rafael Hernández (2005, pp. 21-22): "Martí se sabe parte de una evolución sociocultural y se enorgullece 
de su linaje como latinoamericano y aun como cubano. [...] Su Modernismo acepta y defiende la pluralidad siempre que la esencia identitaria de la nueva literatura no se enajene en productos extranjerizantes".

Hace ya diez años, cuando visité por primera vez Cuba, y mientras recorría los pasillos de Casa de las Américas, encontré un cartel inolvidable: una imagen fotográfica en sepia de José Martí, sobre un fondo blanco, y una leyenda como encabezado de aquella composición que rezaba así: "No hay más que un modo de vivir después de muerto: haber sido un hombre de todos los tiempos o un hombre de su tiempo". Martí optó por lo primero, y es latinoamericano de proyección universal al que vamos a encontrar en las páginas de este obra, que nos deja ver el genio literario, el rigor periodístico y el compromiso ético-político que imprimió a sus crónicas: género que cultivó con especial esmero y al que, no en vano, llegó a definir alguna vez como la novela de la historia. ¡Bienvenido sea este libro, por sus méritos y su urgente necesidad, a las bibliotecas y universidades de la gran casa nuestroamericana!

\section{Referencias:}

Escobar, F. y Rivera, A. (XXXX). Nuestro modo de contar la realidad. Suplemento Cultural. Recuperado de: http://www.icat.una.ac. $\mathrm{cr} /$ suplemento_cultural/index. $\mathrm{php} / \mathrm{en} /$ the-community/119-literatura-y-musica/629-nuestro-modo-de-narrar-la-realidad-froilan-escobar-ernesto-rivera381

Hernández. L. (2005). Martí y la vigencia de su proyecto modernista. Hipertexto, (1), pp. 20-26

Ortiz, R. (1995). Cultura, modernidad e identidades. Nueva Sociedad, 137, pp. 17-23. 